\title{
In vitro elution characteristics of gentamicin-impregnated Polymethylmethacrylate: premixed with a second powder vs. liquid Lyophilization
}

Wongthawat Liawrungrueang ${ }^{1}$, Suwipa Ungphaiboon², Arnurai Jitsurong ${ }^{3}$, Natnicha Ingviya4, Boonsin Tangtrakulwanich ${ }^{1}$ and Varah Yuenyongviwat ${ }^{1 *}$ (i)

\begin{abstract}
Background: Antibiotic-loaded bone cement, or antibiotic-impregnated polymethylmethacrylate (PMMA), were developed to prevent and treat bone and joint infections. Gentamicin is an antibiotic that is commonly used in combination with PMMA; however, gentamicin powder is hard to obtain in many countries. This study aimed to evaluate the elution characteristics of gentamicin-impregnated PMMA made with lyophilized liquid gentamicin, compared with PMMA; which is made from commercial gentamicin powder.

Methods: The experimental sample was divided into 2 groups: the gentamicin power group (PG-PMMA) and the lyophilized liquid gentamicin group (LG-PMMA). Ten cement spacers were prepared in each group. These were produced by mixing gentamicin powder, or lyophilized liquid gentamicin, with a powder polymer before adding the liquid monomer ( $2 \mathrm{~g}$ of gentamicin and $40 \mathrm{~g}$ of PMMA). The volume and surface area of the antibioticimpregnated cement spacers were $50 \mathrm{~cm}^{3}$ and $110 \mathrm{~cm}^{2}$, respectively. Each spacer was immersed in phosphatebuffered saline, which was changed daily under sterile conditions. The solutions were collected to measure the level of gentamicin using the enzyme multiplied immunoassay technique (EMIT), at days 1, 2, 3, 4, 5, 6, 7, 14, 21, 28, 35 and 42.

Results: The collections from both groups had high concentrations of gentamicin on day $1(113.63 \pm 23.42 \mathrm{mg} / \mathrm{dL}$ in LG-PMMA and $61.7 \pm 8.37 \mathrm{mg} / \mathrm{dL}$ in PG-PMMA), but experienced a continuous decrease over time. The PMMA spacers from both groups could release gentamicin for up to 6 weeks $(3.28 \pm 1.17 \mathrm{mg} / \mathrm{dL}$ in LG-PMMA and $1.21 \pm$ $0.28 \mathrm{mg} / \mathrm{dL}$ in PG-PMMA). However, there were significantly higher levels of gentamicin concentrations in the LGPMMA group compared to the PG-PMMA group at all time points $(P<0.05)$.

Conclusion: Gentamicin-impregnated PMMA made with lyophilized liquid gentamicin had approximately a two times higher rate of antibiotic elution in preliminary in vitro studies, as compared with PMMA made with premixed gentamicin powder.
\end{abstract}

Keywords: Antibiotic spacer, Elution characteristics, Lyophilization, Liquid gentamicin

*Correspondence: varahortho@gmail.com

'Department of Orthopedics, Faculty of Medicine, Prince of Songkla University, Hat Yai, Songkhla 90110, Thailand

Full list of author information is available at the end of the article

C C The Author(s). 2021 Open Access This article is licensed under a Creative Commons Attribution 4.0 International License, which permits use, sharing, adaptation, distribution and reproduction in any medium or format, as long as you give appropriate credit to the original author(s) and the source, provide a link to the Creative Commons licence, and indicate if changes were made. The images or other third party material in this article are included in the article's Creative Commons licence, unless indicated otherwise in a credit line to the material. If material is not included in the article's Creative Commons licence and your intended use is not permitted by statutory regulation or exceeds the permitted use, you will need to obtain permission directly from the copyright holder. To view a copy of this licence, visit http://creativecommons.org/licenses/by/4.0/. The Creative Commons Public Domain Dedication waiver (http://creativecommons.org/publicdomain/zero/1.0/) applies to the data made available in this article, unless otherwise stated in a credit line to the data. 


\section{Background}

Osteomyelitis and periprosthetic joint infections are serious conditions, which lead to significant morbidity, require prolonged treatment and are associated with high rates of recurrence [1, 2]. Antibiotic-loaded bone cement, or antibiotic-impregnated polymethylmethacrylate (PMMA), has been developed to treat chronic osteomyelitis and periprosthetic infections [2]. The benefit of antibiotic-impregnated PMMA is its ability to provide a local concentration of antibiotics to eradicate infection [3], which limits the side effects associated with systemic antibiotics [4]. Gentamicin is one of the antibiotics commonly used to mix with PMMA [1]. If physicians require higher concentrations of gentamicin; when preparing handmade PMMA beads or articulating spacers, gentamicin in powder form is normally used for mixing with PMMA. The reason for this is that most of the available, commercial gentamicin-impregnated PMMA, contains only $0.5-1 \mathrm{~g}$ of gentamicin in batches of bone cement (40 g) [5]. However, gentamicin powder is difficult to obtain in some countries where only liquid gentamicin is available [6]. Another drawback of gentamicin powder is its substantially higher cost compared with liquid gentamicin [7]. A previous study reported that gentamicin powder costs approximately 10 times more than liquid gentamicin [2]. Earlier studies have reported the results of gentamicin-impregnated PMMA made with liquid gentamicin $[2,7]$, and in both of these reports, the dose of gentamicin mixed with a pack of cement was $480 \mathrm{mg}$. However, preparing handmade gentamicin-impregnated PMMA with liquid gentamicin, in order to obtain a higher concentration of gentamicin, was precluded. As an example; if a physician wanted to add $2 \mathrm{~g}$ of gentamicin to $40 \mathrm{~g}$ of PMMA, the procedure requires $50 \mathrm{ml}$ of liquid gentamicin [Gentamicin $80 \mathrm{mg} / 2 \mathrm{ml}$ ], so not all of the liquid gentamicin can be mixed with the liquid monomer and cement powder. This is because the high volume of normal saline, which is solvent in liquid gentamicin, will dilute the liquid monomer and prevent the hardening of PMMA. This means that liquid gentamicin cannot be realistically used to produce highconcentrations gentamicin PMMA.

The lyophilization technique, or freeze drying, is a process of dehydration via the lowering of temperature until water freezes; this enables water to change directly from its solid phase to its gas phase. This process is commonplace in procedures of pharmaceutical formulations [8]. However, due to availability limitations, and the high cost of gentamicin powder we believe that lyophilized liquid gentamicin could also be used to make gentamicin-impregnated PMMA. Hence, the aim of this study was to evaluate the elution characteristics of gentamicin-impregnated PMMA made with lyophilized liquid gentamicin, as compared to that of PMMA made with commercial gentamicin powder; using the enzyme multiplied immunoassay technique (EMIT) [9].

\section{Method}

This was an experimental study that compared the elution properties of gentamicin from cement spacers made with gentamicin powder and lyophilized liquid gentamicin. The research was approved by the Ethics Committee and Institutional Review Board of the Faculty of Medicine, Prince of Songkla University, Thailand. The experimental samples were divided into 2 groups. In the first group, the gentamicin powder group (PG-PMMA), 10 cement spacers were made by mixing $40 \mathrm{~g}$ of methylmethacrylate polymer (Palacos ${ }^{\oplus} \mathrm{R}$ bone cement; Heraeus Kulzer $\mathrm{GmbH}$, Wehrheim, Germany) with $2 \mathrm{~g}$ of gentamicin powder (Gentamicin sulphate; Yantai Justaware Pharmaceutical Ltd., Yantai, China) in a sterile bowl (Fig.1a). The liquid monomer was then added into the bowl. The polymer, gentamicin and the liquid monomer were hand-mixed, and then placed in the pre-defined molds (via $50 \mathrm{ml}$-syringe) during the dough stage. The volume and surface area of the antibiotic-impregnated cement spacers were $50 \mathrm{~cm}^{3}$ and $110 \mathrm{~cm}^{3}$, respectively (Fig.1b and c).

The second group, the lyophilized liquid gentamicin group (LG-PMMA), consisting of 10 cement spacers prepared following the same steps as those for the gentamicin powder group; with the exception of using $2 \mathrm{~g}$ of lyophilized liquid gentamicin. These were produced by the freeze-drying process (this removes water from a product after it is frozen and placed under a vacuum) for a total of 25 vials of liquid gentamicin [Gentamicin $80 \mathrm{mg} / 2 \mathrm{ml}$ (1 vial) (Abbott Laboratories, North Chicago, Illinois)]. (Fig.1d).

The cement spacers were removed from the syringe after the cement had set and cooled down. Then each cement spacer was placed in a $150-\mathrm{ml}$ sterile bottle, filled with $100 \mathrm{ml}$ of sterile phosphate-buffered saline (PBS) solution, at a $\mathrm{pH}$ of 7.4 (Sigma-Aldrich Corp., St. Louis, Missouri) for preparation of a standard elusion test. All cement spacers were fully immersed in PBS, after which the bottles were covered and then placed in an incubator at $37^{\circ} \mathrm{C}$. The PBS solution in each bottle was changed every day, with $100 \mathrm{~mL}$ sterile PBS solution for 6 weeks. On days 1, 2, 3, 4, 5, 6, 7, 14, 21, 28, 35, and 42 the solutions were sent to evaluate their elution of gentamicin. The Enzyme Multiplied Immunoassay Technique (EMIT) was used to evaluate the elution characteristics of gentamicin. A fluorescence polarization immunoassay (FPIA) (Abbot, Wiesbaden, Germany) was used to determine the concentrations of gentamicin released. Both LG-PMMA and PG-PMMA spacers were analyzed with a scanning electron microscope [ver. Quanta 400 (SEM-Quanta)] for surface evaluation [10]. 


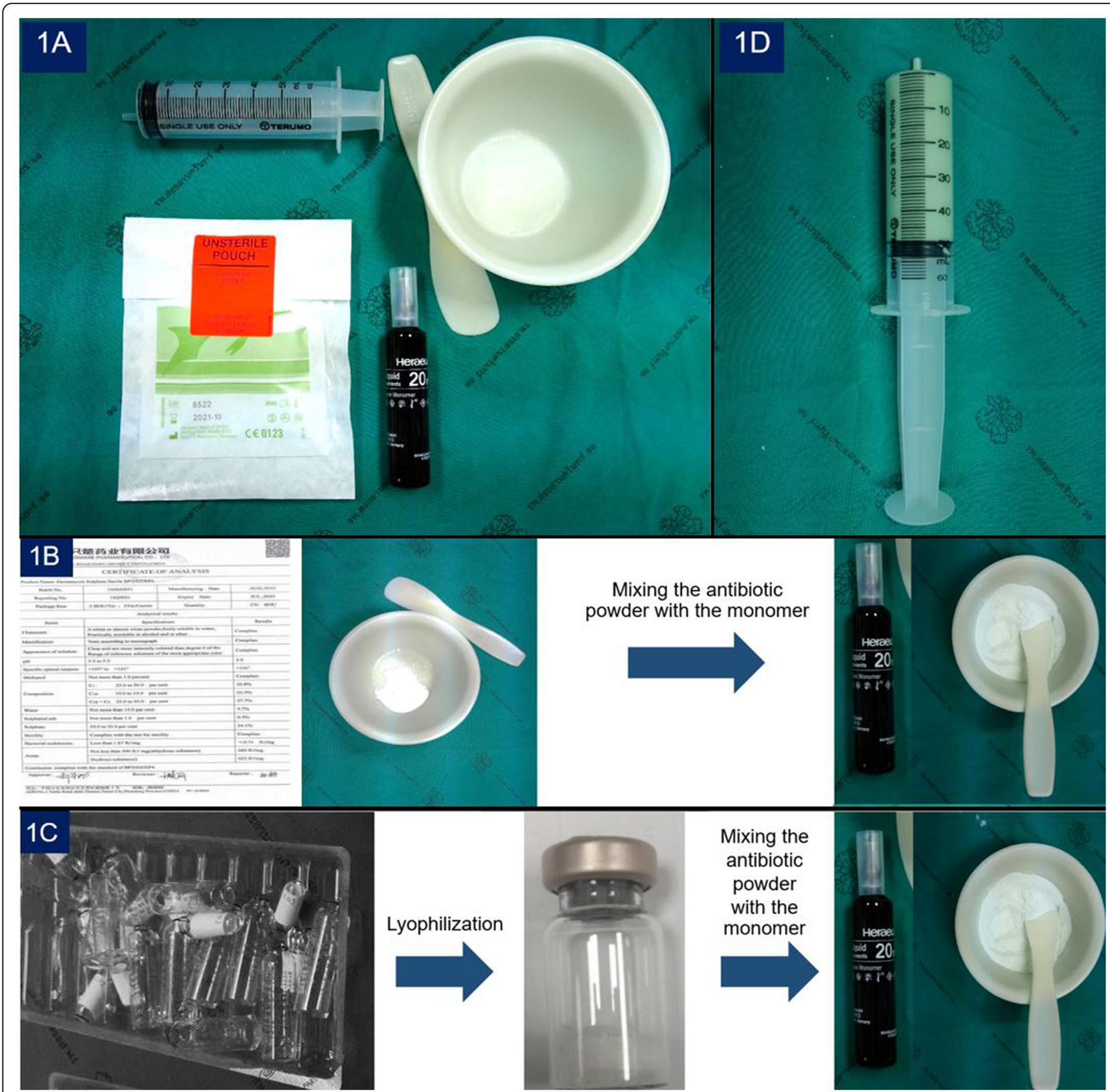

Fig. 1 Forty grams of methylmethacrylate polymer (Palacos ${ }^{\circledR}$ R bone cement; Heraeus Kulzer $\mathrm{GmbH}$, Wehrheim, Germany) mixed with $2 \mathrm{~g}$ of gentamicin powder (1a); $50 \mathrm{ml}$-syringe filled with the polymer-gentamicin mixture in the dough stage to create the uniformed, cylinder shapes of the cement spacers (1) b); PG-PMMA spacer group (1c) and LG-PMMA spacer group (1d)

\section{Statistical analysis}

$\mathrm{R}$ software version 3.1.0 ( $\mathrm{R}$ Foundation for Statistical Computing, Vienna, Austria) was used for statistical analysis. The gentamicin concentration between time points in both groups was evaluated using Student t-test. The differences in gentamicin concentration between the groups, along the 6 weeks of study, were evaluated using Generalized Estimating Equations (GEE). A p-value less than 0.05 was considered to indicate a statistically significant difference.

\section{Results}

The concentrations of gentamicin from the samples of both groups are shown in Table 1 . All of the samples had a high concentration of gentamicin on day 1, which decreased continuously over time. The PMMA spacers from both groups could release gentamicin until the 6th week of study. However, the gentamicin concentrations in the LG-PMMA group were significant higher compared to those of the PG-PMMA group at all time points $(P<0.05)$. 
Table 1 Mean gentamicin concentration

\begin{tabular}{|c|c|c|c|c|}
\hline \multirow[t]{2}{*}{ Samples } & \multicolumn{3}{|l|}{ Group } & \multirow[t]{2}{*}{$p$-value } \\
\hline & $\begin{array}{l}\text { PG-PMMA } \\
\text { Mean (SD) } \\
(\mathrm{mg} / \mathrm{dL})\end{array}$ & $\begin{array}{l}\text { LG-PMMA } \\
\text { Mean (SD) } \\
\text { (mg/dL) }\end{array}$ & $\begin{array}{l}\text { Mean difference (SD) } \\
\text { (mg/dL) }\end{array}$ & \\
\hline Day 1 & $61.7(8.37)$ & $113.63(23.42)$ & $51.93(7.86)$ & $<0.001$ \\
\hline Day 2 & $9.26(1.43)$ & $34.04(5.25)$ & $24.77(1.72)$ & $<0.001$ \\
\hline Day 3 & $5.06(0.49)$ & $29.39(4.49)$ & $24.32(1.43)$ & $<0.001$ \\
\hline Day 4 & $4.49(0.67)$ & $22.28(2.71)$ & $17.78(0.88)$ & $<0.001$ \\
\hline Day 5 & $3.63(0.88)$ & $18.81(3.3)$ & $15.18(1.08)$ & $<0.001$ \\
\hline Day 6 & $3.18(0.67)$ & $16.1(2.55)$ & $12.92(0.83)$ & $<0.001$ \\
\hline Day 7 & $3.13(0.48)$ & $14.18(2.44)$ & $11.0 .5(0.76)$ & $<0.001$ \\
\hline Day 14 & $2.53(0.76)$ & $7.02(3.12)$ & $4.5(1.02)$ & $<0.001$ \\
\hline Day 21 & $2.05(0.33)$ & $5.9(1)$ & $3.85(0.33)$ & $<0.001$ \\
\hline Day 28 & $1.71(0.036)$ & $5.98(1.42)$ & $4.27((0.46)$ & $<0.001$ \\
\hline Day 35 & $1.56(0.29)$ & $4.97(0.79)$ & $3.41(0.27)$ & $<0.001$ \\
\hline Day 42 & $1.21(0.28)$ & $3.28(1.17)$ & $2.08(0.38)$ & $<0.001$ \\
\hline
\end{tabular}

GEE analysis also showed that the LG-PMMA group showed a significantly higher gentamicin concentration than the PG-PMMA group along the 6-week study period ( $p<0.05)$ (Fig.2). Results of the scanning electron microscope (SEM) evaluation indicated that the surface area of the LG-PMMA spacers (Fig. 3a) were more porous than their PG-PMMA counterparts. (Fig. 3b).

\section{Discussion}

The most important benefit of antibiotic-impregnated cement is its ability to provide a high concentration of antibiotics at the local site [11]. Antibiotic-impregnated cement is a treatment option for osteomyelitis and periprosthetic infections [2]. Gentamicin is one of the antibiotics commonly used in the preparation of antibiotic PMMA [12-15]. Gentamicin powder is commonly used as a component to produce antibiotic PMMA; however, there is limited availability in certain countries, while the liquid form of gentamicin is more readily available and has a lower cost. Therefore, the authors conducted this research to evaluate the elution characteristics of gentamicin-impregnated PMMA made with lyophilized liquid gentamicin, as compared with PMMA made with commercial gentamicin powder.

This study found that antibiotic-impregnated PMMA, using lyophilized liquid gentamicin, exhibited excellent elution characteristics compared to PMMA produced with gentamicin powder. The reason for this result can be found in previous studies; wherein, a previous report claimed that increasing the porosity of antibioticimpregnated PMMA increases the antibiotic elution rate [16]. Furthermore, another study reported that adding

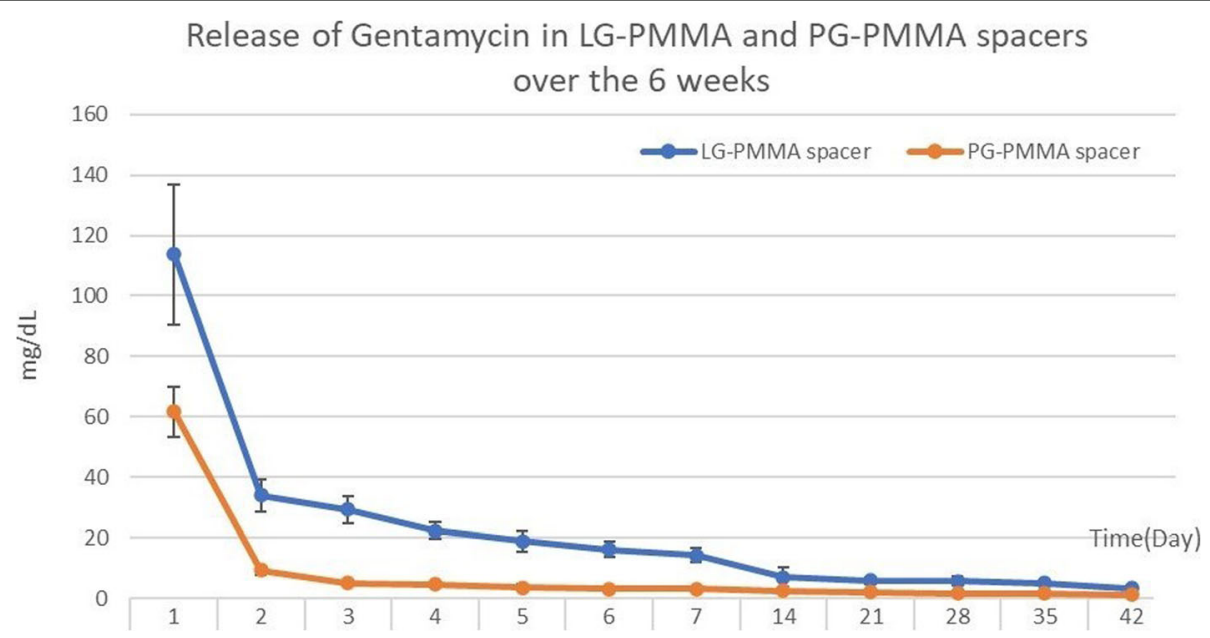

Fig. 2 Concentration of eluted gentamicin in LG-PMMA and PG-PMMA groups during the 6-week study period 


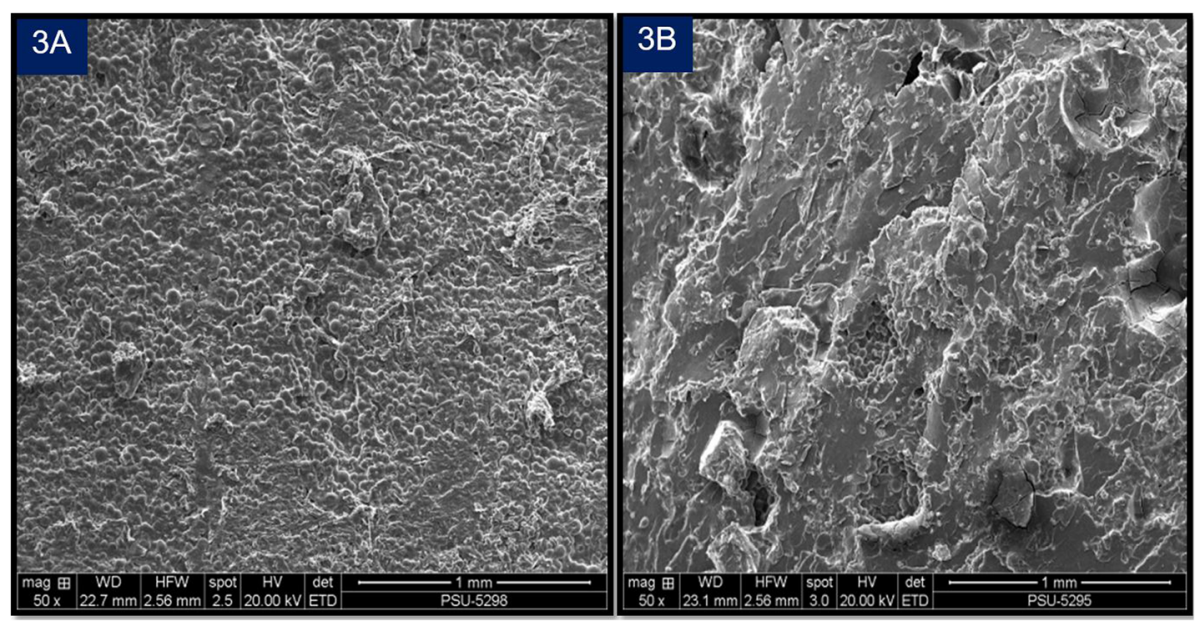

Fig. 3 Scanning electron microscope images of the surface of PMMA spacers (3a) LG-PMMA spacer; (3b) PG-PMMA spacer. The picture of the LGPMMA spacer showed greater density of small uniformed, rounded shape pores; while the PG-PMMA spacer had a smoother surface area

glycine as a filler in hand-mixed PMMA could increase the elution of gentamicin, by increasing the porosity of the spacer's surface [17]. We hypothesized that since the liquid gentamicin ampule employed in our study also contained sodium hydroxide, methylparaben, and sodium metabisulfite, after lyophilization, these substances might serve as fillers; and therefore, increase the porosity of LG-PMMA spacers. Our study used a hand mixing technique instead of vacuum-mixing or centrifugation mixing, because these two methods would decrease the porosity of the cement, which in turn would decrease the elution properties of the antibiotics [18].

This study has a number of limitations. First, this study used a hand mixing method that was a potential source of variability; hence, the resultant porosity may vary significantly. It would be more appropriate to use a standardized mixing approach with a device. Therefore, further research in clinical settings is needed to confirm these results before applying them in standard clinical practice. Second, the results from the scanning electron microscope (SEM) were obtained from direct inspection of the surface appearance of the cement spacers; instead of direct measurement of pore size. Finally, this study was only a quantitative study of gentamicin elution without microbiological study. However, the antimicrobial effectiveness of our in-house lyophilized gentamicin was confirmed via disk diffusion method (Agar diffusion test), for antibiotic susceptibility testing Fig. 4. The specific microorganisms in the method were: Staphylococcus aureus ATCC 25923 (S. aureus) for Gram-positive bacteria (GPB) and Escherichia coli ATCC 25922 (E.coli) for Gram-negative bacteria (GNB). The results showed lyophilized gentamicin had an antimicrobial effect. The sterile filter paper discs $(6 \mathrm{~mm})$, containing $10 \mu \mathrm{l}$ of lyophilized gentamicin solution (concentration $39.06 \mu \mathrm{g}$ $/ \mathrm{ml}$ ), demonstrated a $15 \mathrm{~mm}$ inhibition zone for E.coli

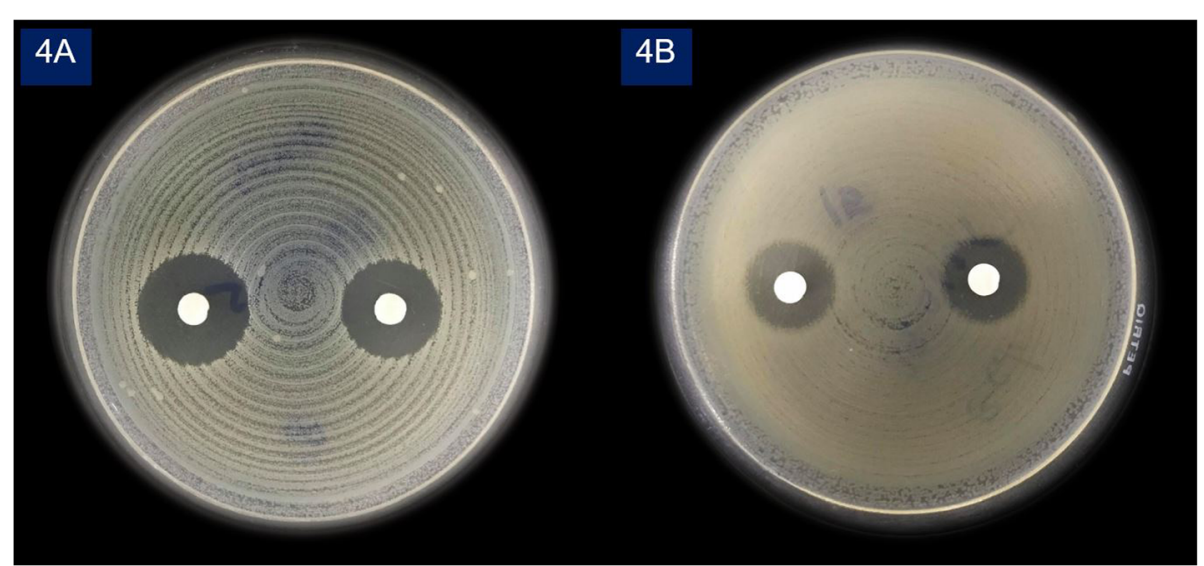

Fig. 4 Disk diffusion method for antibiotic susceptibility testing; (4a) Staphylococcus aureus ATCC 25923, (4b) Escherichia coli ATCC 25922 
and an $18 \mathrm{~mm}$ inhibition zone for $\mathrm{S}$ aureus. This reached the sensitive level $(\geq 15 \mathrm{~mm}$ ) of standard laboratory testing, which used commercial antibiotic discs that contained Gentamicin $10 \mu \mathrm{g}$ [19]. So, we believe that PMMA spacers made of lyophilized liquid gentamicin should also achieve antimicrobial effectiveness. However, further research for comparing microbiological effects between lyophilized liquid gentamicin with gentamicin powder might be beneficial.

\section{Conclusion}

Gentamicin-impregnated PMMA made with lyophilized liquid gentamicin had approximately a two times higher rate of antibiotic elution in preliminary in vitro studies, comparing with PMMA made from premixed gentamicin powder. This regimen could be utilized in centers with limited availability of premixed gentamicin powder to treat bone and joint infections.

\section{Acknowledgements}

The authors wish to thank Andrew Jonathan Tait, from the International Affairs Department, for his assistance in proofreading the English of this report.

\section{Authors' contributions}

WL: Study design, data collection, statistical analysis, and writing the paper; SU, AJ: Data collection; BT: Study design and statistical analysis; VY: Corresponding author, study design, statistical analysis, and writing the paper. All authors have read and approved the final manuscript.

\section{Funding}

Funding for this research was provided by the Faculty of Medicine, Prince of Songkla University, Songkhla, Thailand (grant number 59-332-11-1). The funders had no role in study design, data collection and analysis, decision to publish, nor preparation of the manuscript.

\section{Availability of data and materials}

The datasets generated during this current study are available from the corresponding author upon reasonable request.

\section{Ethics approval and consent to participate}

This study was approved by the Ethics Committee and Institutional Review Board of the Faculty of Medicine, Prince of Songkla University. Consent to participate: Not applicable.

\section{Consent for publication}

Not Applicable.

\section{Competing interests}

The authors declare that they have no competing interests.

\section{Author details}

'Department of Orthopedics, Faculty of Medicine, Prince of Songkla University, Hat Yai, Songkhla 90110, Thailand. ${ }^{2}$ Department of Pharmaceutical Technology, Faculty of Pharmaceutical Science, Prince of Songkla University, Hat Yai, Thailand. ${ }^{3}$ Forensic Medicine and Toxicology Unit, Department of Pathology, Faculty of Medicine, Prince of Songkla University, Hat Yai, Thailand. ${ }^{4}$ Microbiology Unit, Department of Pathology, Faculty of Medicine, Prince of Songkla University, Hat Yai, Thailand.
Received: 26 May 2020 Accepted: 26 December 2020

Published online: 04 January 2021

\section{References}

1. Kavanagh N, Ryan EJ, Widaa A, Sexton G, Fennell J, O'Rourke S, et al. Staphylococcal osteomyelitis: disease progression, treatment challenges, and future directions. Clin Microbiol Rev. 2018;31(2):e00084-17.

2. Bistolfi A, Massazza G, Verné E, Massè A, Deledda D, Ferraris S, et al. Antibiotic-loaded cement in orthopedic surgery: a review. ISRN Orthop. 2011;2011:290851

3. Buchholz HW, Engelbrecht $\mathrm{H}$. Depot effects of various antibiotics mixed with Palacos resins. Chir Z Alle Geb Oper Medizen. 1970 Nov;41(11):511-5.

4. Springer BD, Lee G-C, Osmon D, Haidukewych GJ, Hanssen AD, Jacofsky DJ. Systemic safety of high-dose antibiotic-loaded cement spacers after resection of an infected total knee arthroplasty. Clin Orthop. 2004 Oct;427: 47-51.

5. Neut D, Kluin OS, Thompson J, van der Mei HC, Busscher HJ. Gentamicin release from commercially-available gentamicin-loaded PMMA bone cements in a prosthesis-related interfacial gap model and their antibacterial efficacy. BMC Musculoskelet Disord. 2010;11:258.

6. Hosseinzadeh HRS, Emami M, Lahiji F, Shahi AS, Masoudi A, Emami S. The Acrylic Bone Cement in Arthroplasty, Arthroplasty - Update, Plamen Kinov. London: IntechOpen; 2013. https://doi.org/10.5772/53252. Available from: https://www.intechopen.com/books/arthroplasty-update/the-acrylic-bonecement-in-arthroplasty.

7. Seldes RM, Winiarsky R, Jordan LC, Baldini T, Brause B, Zodda F, et al. Liquid gentamicin in bone cement: a laboratory study of a potentially more costeffective cement spacer. J Bone Joint Surg Am. 2005;87(2):268-72.

8. Izutsu K-I. Applications of freezing and freeze-drying in pharmaceutical formulations. Adv Exp Med Biol. 2018;1081:371-83.

9. Johnston A, Holt DW. Immunosuppressant drugs--the role of therapeutic drug monitoring. Br J Clin Pharmacol. 2001;52(Suppl 1):61S-73S

10. Evgin T, Turgut A, Hamaoui G, Spitalsky Z, Horny N, Micusik M, et al. Size effects of graphene nanoplatelets on the properties of high-density polyethylene nanocomposites: morphological, thermal, electrical, and mechanical characterization. Beilstein J Nanotechnol. 2020;11:167-79.

11. Dieckmann R, Schmidt-Braekling T, Gosheger G, Theil C, Hardes J, Moellenbeck B. Two stage revision with a proximal femur replacement. BMC Musculoskelet Disord. 2019;20(1):58.

12. Zhang J, Zhang X-Y, Jiang F-L, Wu Y-P, Yang B-B, Liu Z-Y, et al. Antibioticimpregnated bone cement for preventing infection in patients receiving primary total hip and knee arthroplasty: a meta-analysis. Medicine (Baltimore). 2019 Dec;98(49):e18068.

13. Hipfl C, Winkler T, Janz V, Perka C, Müller M. Management of Chronically Infected Total Knee Arthroplasty with Severe Bone Loss Using Static Spacers with Intramedullary Rods. J Arthroplast. 2019:34(7):1462-9.

14. Segawa H, Tsukayama DT, Kyle RF, Becker DA, Gustilo RB. Infection after total knee arthroplasty. A retrospective study of the treatment of eighty-one infections. J Bone Joint Surg Am. 1999;81(10):1434-45.

15. Atkins BL, Athanasou N, Deeks JJ, Crook DW, Simpson H, Peto TE, et al. Prospective evaluation of criteria for microbiological diagnosis of prostheticjoint infection at revision arthroplasty. The OSIRIS collaborative study group. J Clin Microbiol. 1998;36(10):2932-9.

16. Shiramizu K, Lovric V, Leung A, Walsh WR. How do porosity-inducing techniques affect antibiotic elution from bone cement? An in vitro comparison between hydrogen peroxide and a mechanical mixer. J Orthop Traumatol Off J Ital Soc Orthop Traumatol. 2008:9(1):17-22.

17. McLaren AC, Nelson CL, McLaren SG, DeCLerk GR. The effect of glycine filler on the elution rate of gentamicin from acrylic bone cement: a pilot study. Clin Orthop. 2004:427:25-7.

18. Wixson RL. Do we need to vacuum mix or centrifuge cement? Clin Orthop Relat Res. 1992;285:84-90.

19. Hombach $M$, Böttger EC, Roos $M$. The critical influence of the intermediate category on interpretation errors in revised EUCAST and CLSI antimicrobial susceptibility testing guidelines. Clin Microbiol Infect. 2013;19(2):E59-71.

\section{Publisher's Note}

Springer Nature remains neutral with regard to jurisdictional claims in published maps and institutional affiliations. 